\title{
DIAGNOSTIC ISSUES OF ALLERGIC PHARINGITIS
}

\author{
PUKHLIK Sergey, SUVORKINA Alisa
}

Odessa National Medical University, Odessa, Ukraine

Corresponding Author: SUVORKINA Alisa, E-mail: $\underline{\text { drsuvorkina@ukr.net }}$

Abstract

This article gives characteristics to the problem of chronic pharyngitis. It describes the lack of modern etiopathogenetic classification, subjective approach to diagnosis, estimates the role of allergic inflammation in the formation of chronic pharyngitis. It was offered a questionnaire revealing the influence of a patient's somatic status on the development of anxiety disorder and depression. We used a diagnostic algorithm for chronic pharyngitis, which includes not only the clinical examination and history, but also a psychosomatic condition questionnaire; $\mathrm{CBC}$, cytological examination of nasal and pharyngeal mucosal secretions, concentration of general and specific IgE; and if necessary, allergy consultation. It can allow an individual approach to the treatment of patients with chronic pharyngitis depending on etiopathogenesis, which will improve their quality of life.

Key words: chronic pharyngitis, allergy, diagnostic algorithm, questionnaire,

\section{Introduction}

Chronic pharyngitis (CP) is one of the most common pathologies of the upper respiratory tract, which relates to one of the insufficiently explored pathology in modern otorhinolaryngology. CP occupy a leading position in the outpatient practice of otorhinolaryngologists (1). However, the statistics on this pathology are incomplete, as a plenty of patients can be treated by general practitioners, gastroenterologists, neuropathologists, and other related specialists.

In the literature, the term "tonsillopharyngitis" or "pharyngotonsillitis" is widely used (2), although it is absent in ICD-10 and in planned ICD-11.

The etiology and pathogenesis of chronic pharyngitis, which, according to most authors, is a polyetiological disease, are discussed. All existing sources on this subject emphasize that the etiology and pathogenesis of chronic pharyngitis is not well understood. The base of the pathogenesis of $\mathrm{CP}$ remains controversial, and today the search for relationships of pathological changes in the upper respiratory tract with the influence of related and concomitant pathology remains relevant (3).

In most cases, acute pharyngitis occurs with acute respiratory viral infection and does not require any treatment, because it passes on its own in a few days, so it is difficult to imagine that the acute process in the oropharynx becomes chronic.

Chronic pharyngitis is an inflammation of the mucous membrane of the upper respiratory tract, has a slow character and is often difficult to treat. We should emphasize here that the suffix "itis", usually implying an inflammatory pathology, actually covers a number of conditions that are not always associated with infection.

V. Renner et al (2012) give the most concise definition: chronic pharyngitis is inflammation of the oropharynx (4). Often in foreign publications pharyngitis is called "sore throat".

The pharynx is an aero digestive crossroads that participates in the processes of respiration, swallowing, phonation, taste and smell. Therefore, the symptom complex that occurs with this pathology is various and includes: sore throat, sore throat, burning, coughing, choking, feeling a «lump» in the throat, unpleasant aftertaste in the mouth, impaired swallowing, and in some cases, disturbed sleep, appetite, feeling of nervousness. All this reduces the quality of life of the patient and leads to a disturbance of psychosomatic health $(5,6)$.

Clinical manifestations vary depending on etiopathogenetic factors. The pathogenesis of chronic pharyngitis also includes neurophysiological mechanisms and the mechanism of the L-form of bacteria that cause speech disorders in patients with chronic pharyngitis (7).An individual approach to the treatment of chronic pharyngitis is better than traditional treatment. This is important while choosing a treatment option (8). 
There is a single concept of upper respiratory tract diseases that gets widespread recognition. However, most researchers pay attention only to the effect of rhinosinusitis, while ignoring the factors of the pharynx in the lower respiratory tract, especially with the allergic nature of pharyngitis, which has not been fully covered till today (9).

Back in the last century, scientists took an interest in the role of allergy in the pathogenesis of chronic pharyngitis. The most likely symptom in chronic pharyngitis of an allergic nature remains a tickling in the throat, probably of spasmodic etiology comparable to the effect of sneezing. Most likely, it is allergic, since it is not present either with paresthesia of the pharynx of organic origin, or with many dysesthesias that point to a psychosomatic process (10). However, it is still an open question.

Today allergic diseases represent a global health problem that affects $10-25 \%$ of the world's population. Pharyngeal symptoms occur in more than $50 \%$ of patients with allergic rhinitis (11). Besides the certain types of chronic pharyngitis, this condition is most common in more polluted cities, the causes of which are dust, smoke and industrial pollutants. This can provoke repeated attacks of allergic or vasomotor rhinitis with a secondary infection, catarrhal symptoms in the nasal cavity and recurrent or persistent inflammation of the pharynx. As a result, a condition of increased sensitivity of the mucous membrane of the nose and throat occurs. (12).

There is clear evidence in support of the concept that allergic diseases are influenced by genetic predisposition and environmental exposure (13). Therefore, while taking a patient history, it is necessary to pay attention to a family history.

Modern science distinguishes pathologies of allergic etiology with clinical manifestations in the mucous membranes. Allergic conjunctivitis or conjunctival symptoms are present in $30-71 \%$ of patients with allergic rhinitis $(14,15)$. Eosinophilic esophagitis is considered a specific form of food allergy. Most of these patients also have atopic diseases (asthma, allergic rhinitis, atopic dermatitis). The main symptoms in these diseases are swallowing disorders, pain and discomfort while swallowing saliva or food, burning behind the sternum, belching, and feeling of a «lump» or foreign body behind the sternum $(16,17)$. In the description of these symptom complexes, lots of symptoms are inherent in inflammation of the pharynx: pain, soreness, burning, swallowing disorders, changes in taste, etc.
In recent years, the term "oral allergy syndrome OAS" or "pollen-food allergy syndrome" has appeared in the literature. "Oral allergy syndrome" (SOA) is a type of food allergy caused by various flavors, food additives, nuts, fruits and vegetables. Typical symptom is itching in the oral cavity and throat, which occurs almost immediately after ingestion of food in the oral cavity, and lasts until the food is swallowed. A number of authors (18) indicate that the frequency of SOA is $5-8 \%$; and conditions up to anaphylaxis occur in $1-2 \%$ of patients. Pollen from birch, ragweed and other herbs can also cause SOA, which occurs at any time of the year.

Food allergies affect up to $6 \%$ of young children, most of which "outgrow" sensitivity, and about $2 \%$ of the total population (19). Food allergic reactions cause various symptoms associated with the skin, the gastrointestinal tract and the respiratory tract, and may be associated with IgE-mediated and nonIgE-mediated response. The adaptive immune system of the mucous membrane is especially skilled in suppressing responses to non-hazardous antigens (oral tolerance) $(20,21)$.

Why did the pharynx, which is exposed to both respiratory and food allergens, fall out of the attention of modern science?

Based on the foregoing, we have developed a diagnostic algorithm for examining such patients.

The purposeof our work was to identify patients with an allergic form of chronic pharyngitis.

\section{Material and methods}

The retrospective study included 101 patients. We distinguished 3 groups of patients: grope 1 - 35 patients with gastrointestinal diseases (reflux esophagitis); grope 2 - 30 patients with psychosomatic disorders - determined by the psychosomatic questionnaire, the absence of local symptoms of inflammation; grope 3 - 36 patients with the allergic nature of the disease.

In the first group, the following complaints were: sore throat and burning, unpleasant aftertaste in the mouth, choking, frequent heartburn. An allergic history is not burdened. There were no other complaints from the ENT organs. Seasonality of complaints is not observed. Some of these patients are examined and observed by gastroenterologists and have gastroesophageal reflux disease.

In the second group patients complained of feeling of a "lump" in the throat, sore, choking, which is 
characteristic of chronic pharyngitis, as well as complaints of a lack of appetite, irritability, a feeling of anxiety, nervousness and panic, sleep disorders typical for patients with anxiety disorders and depressions.

In the third group patients had complaints of: sore throat, scratchiness in throat, burning, cough, sneezing, nasal congestion and nasal discharge, lacrimation. In some patients, complaints are seasonal. Some patients have perennial complaints, but have exacerbations in the spring-summer period, as well as the presence of allergic diseases in the family.

\section{Results}

We carefully collected a medical history of all patients. We used a questionnaire, which includes: an Anamnesis of current disease, family history, allergic anamnesis, the presence of complaints of chronic pharyngitis (Table 1). We also use a questionnaire that identifies the influence of the somatic status of the patient in the development of anxiety and depression, based on Generalized Anxiety Disorder 7-item (GAD-7) scale, The PHQ9 (Patient Health Questionnaire-9) and the Hospital Anxiety and Depression Scale (HADS). All patients underwent clinical examination - pharyngoscopy, Laboratory and instrumental methods of diagnosis: complete blood count test (CBC), cytological examination of nasal and pharyngeal mucosal secretions; concentration of general and specific $\operatorname{IgE}$ of pharyngeal mucus on the cellular composition;

In the first group, in the picture of pharyngoscopy were symptoms of local inflammation. CBC test and cytological examination of the pharyngeal mucosal secretions included inflammatory changes. No pathological changes were observed in the nasocytogram. Reference values of total serum Ig E were within normal limits.

In the second group of patients, the local symptoms of inflammation were absent. The results of clinical laboratory and instrumental methods of diagnosis showed lack of signs of an inflammation. After analyzing and evaluating the results of test that identifies the influence of the somatic status of the patient in the development of anxiety and depression, subclinically or clinically the expressed depression was detected.

In the third group patients had local signs of inflammation while pharyngoscopy; leukocytosis in $\mathrm{CBC}$ test, an increased number of eosinophils.
Cytological examination of the nasal and pharyngeal mucus: an increased number of leukocytes, with eosinophils prevailing among leukocytes (more than $5 \%$ ), an increase of total E.

\section{Discussion}

Suchwise, we highlighted the main complaints that are inherent in all forms of chronic pharyngitis: perspiration, pain, burning in the throat. However, other complaints may vary. Therefore, it is very important during the initial examination of such patients to use the diagnostic algorithm already at the stage of history taking.

We offer a diagnostic algorithm for chronic pharyngitis:

1) clinical examination;

2) a history taking:

- anamnesis of life (bad habits, working conditions, contact with harmful substances);

- medical history;

- genetic history;

- allergic history due to the time of occurrence of allergy manifestations (persistent or intermittent forms), comorbidity (AR, BA, allergic esophagitis, etc.);

- the presence of chronic diseases of the gastrointestinal tract, especially reflux esophagitis;

- the presence of psychogenic diseases (we use a questionnaire that identifies the influence of the somatic status of the patient in the development of anxiety and depression, based on Generalized Anxiety Disorder 7-item (GAD-7) scale, The PHQ9 (Patient Health Questionnaire-9) and the Hospital Anxiety and Depression Scale (HADS));

3) cytological examination of nasal and pharyngeal mucosal secretions;

4) CBC test;

5) concentration of general and specific $\operatorname{IgE}$ of pharyngeal mucus on the cellular composition;

6) allergist consultation - identification of causally significant allergens (food and / or respiratory), the relationship with oral allergy, etc. 


\section{Conclusion}

Chronic pharyngitis is a multidisciplinary problem that requires comprehensive study with the use of modern diagnostic capabilities. The allergic form of chronic pharyngitis is a local manifestation of a systemic allergic disease, is practically not detected and is not considered during statistical processing, masked under various other diagnoses, and, accordingly, is not treated with adequate anti- allergic approaches and agents. This work is the first attempt to draw attention to the role of allergies in the pathogenesis of chronic inflammation of the pharynx. The use of a diagnostic algorithm at an early stage showed that $30 \%$ of patients with complaints of chronic pharyngitis have an allergic etiology of the disease. This group of patients requires further examination by an allergist.

Table1. Complaints specific to patients with chronic pharyngitis

\begin{tabular}{|c|c|c|c|}
\hline Symptoms & $\begin{array}{l}\text { I group of patients with } \\
\text { concomitant } \\
\text { gastrointestinal pathology }\end{array}$ & $\begin{array}{l}\text { II group of patients } \\
\text { with a violation of } \\
\text { psychosomatic status }\end{array}$ & $\begin{array}{l}\text { III group of patients } \\
\text { with a burdened } \\
\text { history and } \\
\text { manifestations of } \\
\text { allergies }\end{array}$ \\
\hline Sore throat & + & + & + \\
\hline Burning in throat & + & + & + \\
\hline $\begin{array}{l}\text { Scratchiness in } \\
\text { throat }\end{array}$ & + & + & + \\
\hline Cough & & & + \\
\hline Sneezing & & & + \\
\hline $\begin{array}{l}\text { Feeling of a "lump" } \\
\text { in the throat }\end{array}$ & & + & + \\
\hline $\begin{array}{l}\text { Excessive tearing } \\
\text { (lacrimation) }\end{array}$ & & & + \\
\hline Nasal discharge & & & + \\
\hline Nasal congestion & & & + \\
\hline $\begin{array}{l}\text { Breathlessness or a } \\
\text { feeling of } \\
\text { suffocation. }\end{array}$ & & + & + \\
\hline Pyrosis (Heartburn) & + & & \\
\hline $\begin{array}{l}\text { Unpleasant } \\
\text { aftertaste in the } \\
\text { mouth }\end{array}$ & + & & \\
\hline Lack of appetite & + & + & \\
\hline Choking & + & + & \\
\hline $\begin{array}{l}\text { Irritability and } \\
\text { nervousness }\end{array}$ & & + & \\
\hline Sleep disorders & & + & \\
\hline $\begin{array}{l}\text { Feeling of anxiety, } \\
\text { and panic }\end{array}$ & & + & \\
\hline
\end{tabular}




\section{References}

1. Yazici ZM, Sayin I, Kayhan FT, Biskin S. Laryngopharyngeal reflux might play a role on chronic nonspecific pharyngitis. Eur Arch Otorhinolaryngol. 2010 Apr;267(4):571-4. doi: 10.1007/s00405009-1044-2.

2. Stenfors LE, Bye HM, Vorland LH. Remarkable attachment of lactoferrin to Streptococcus pyogenes during acute pharyngotonsillitis. ActaOtolaryngol. 2001;121(5):637-42.

3. Li Z, Huang J, Hu Z. Screening and Diagnosis of Chronic Pharyngitis Based on Deep Learning. Int J Environ Res Public Health. 2019;16(10). doi: 10.3390/ijerph16101688.

4. Renner B, Mueller CA, Shepard A. Environmental and non-infectious factors in the aetiology of pharyngitis (sore throat). Inflamm Res. 2012; 61(10): 1041-52. doi: 10.1007/s00011-012-0540-9.

5. Eyigör $\mathrm{H}$, Arihan $\mathrm{G}$, Ergin $\mathrm{F}$, Barlik $\mathrm{Y}$. [Psychiatric disorder profile in patients with chronic pharyngitis]. Kulak BurunBogazIhtisDerg. $\quad 2006 ; 16(4): 178-82$. [Article in Turkish].

6. Milinevskiı̌ IV, Shabaldina EV, Shamova IP, Shabaldin AV. [The use of the antidepressant citalopran for the treatment of chronic pharyngitis and pharyngeal neurosis]. VestnOtorinolaringol. 2011;(2):58-61.

1. https://pubmed.ncbi.nlm.nih.gov/21512490/ [Article in Russian].

7. Chang MW, Rosendall B, Finlayson BA. Mathematical modeling of the pharyngeal phase of swallowing. J Rehabil Res Dev. 1998;35(3):327-34. https://pubmed.ncbi.nlm.nih.gov/9704316/.

8. 21. Zhao YL, Miao FF, Yang JH. [Individualized treatment of chronic pharyngitis and its clinical significance]. Lin Chung Er Bi Yan HouTou Jing WaiKeZaZhi. 2018 Jul;32(13):1006-1008. doi: 10.13201/j.issn.1001-1781.2018.13.011. [Article in Chinese].

9. Zaidi SH. The role of $\mathrm{H} 2$-receptors in $\mathrm{Ch}$. pharyngitis? J Pak Med Assoc. 2010 Mar; 60 (3Suppl 2):56-7.

10. Filou M, Revel S, Le Guillou F. [Chronic allergic pharyngitis].

PresseThermClim. 1967;104(3):126-7. [Article in French].
11. Modrzyński M, Królikiewicz J, Zawisza E, Przybylski G. The allergic pharyngitis.Medycynarodzinna.2003;(6):199-202.

12. Kumari JO, Rajendran R. Effect of topical nasal steroid spray in the treatment of non-specific recurrent / chronic pharyngitis - a trial study. Indian J Otolaryngol Head Neck Surg. 2008;60(3). doi: 10.1007/s12070-008-0076-Z.

13. Wang DY. Risk factors of allergic rhinitis: genetic or environmental? TherClin Risk Manag. 2005; 1(2):115-23. doi: 10.2147/tcrm.1.2.115.62907.

14. Blochmichel E, Helleboid L, Corvec MP. Chronic allergic conjunctivitis.OculImmunolInflamm. 1993;1(12):9-12. doi: 10.3109/09273949309086529.

15. Leonardi A, Piliego F, Castegnaro A, Lazzarini $\mathrm{D}$, La Gloria Valerio A, et al. Allergic conjunctivitis: a cross-sectional study. ClinExp Allergy. 2015 Jun;45(6):1118-25. doi: 10.1111/cea.12536.

16. Hruz P. Epidemiology of Eosinophilic Esophagitis. Dig Dis. 2014;32(1-2):40-7. doi: 10.1159/000357008.

17. Shoda T, Wen T, Aceves SS, Abonia JP, Atkins $\mathrm{D}$, et al. Eosinophilicoesophagitisendotype classification by molecular, clinical, and histopathological analyses: a cross-sectional study. Lancet GastroenterolHepatol. 2018 Jul;3(7):477-488. doi: $\quad 10.1016 /$ S24681253(18)30096-7.

18. Yagami A, Ebisawa M. New findings, pathophysiology, and antigen analysis in pollenfood allergy syndrome.CurrOpin Allergy ClinImmunol. 2019 Jun;19(3):218-223. doi: 10.1097/ACI.0000000000 000533.

19. Sicherer SH, Sampson HA. Food allergy.J Allergy ClinImmunol. 2006;17(2):470-5. doi: 10.1016/j.jaci.2005.05.048.

20. Sicherer SH, Sampson HA. Food allergy: A review and update on epidemiology, pathogenesis, diagnosis, prevention, and management. J Allergy ClinImmunol. 2018;141(1):41-58. 10.1016/j.jaci.2017.11.003.

21. Wambre E, Jeong D. Oral Tolerance Development and Maintenance. Immunol Allergy Clin North Am. 2018;38(1):27-37. doi: 10.1016/j.iac.2017.09.003. 